\title{
A review of career devoted to Biophotonics - In memoriam to Ekaterina Borisova (1978-2021)
}

Tsanislava Genova ${ }^{1 *}$, Latchezar Avramov ${ }^{1}$, Boyko Kolev ${ }^{1}$, Alexander Gisbrecht ${ }^{1}$, Irina Bliznakova ${ }^{1}$, Lidiya Zaharieva ${ }^{1}$, Victoria Mircheva ${ }^{1}$, Stoyan Ilyov $^{1}$, Ivan Angelov ${ }^{1}$, Vanya Mantareva², Petranka Troyanova ${ }^{3}$, Petya Pavlova ${ }^{4}$, Tatiana Novikova ${ }^{5}$, Razvigor Ossikovski ${ }^{5}$, Deyan Ivanov ${ }^{5}$, Viktor Dremin $^{6,7}$, Edik U. Rafailov' ${ }^{7}$, Sergey G. Sokolovsky ${ }^{7}$, Alexander Bykov ${ }^{8}$, Igor V. Meglinski ${ }^{7,8,9}$, Ivan Bratchenko ${ }^{10}$, Oxana Semyachkina-Glushkovskaya ${ }^{11,12}$, Elina Genina ${ }^{11,13}$, Alexey N. Bashkatov ${ }^{11,13}$, Alla B. Bucharskaya ${ }^{11,13,14}$, Valery Zakharov ${ }^{10}$, Janis Spigulis ${ }^{15}$, Sindhoora Kaniyala Melanthota ${ }^{16}$, Spandana K. U. ${ }^{16}$, Nirmal Mazumder ${ }^{16}$, Shama Prasada K. ${ }^{17}$, Peter Townsend ${ }^{18}$, Luís Oliveira ${ }^{19,20}$, Alexander V. Priezzhev ${ }^{21}$, Dick (H.J.C.M.) Sterenborg ${ }^{22,23}$, and Valery V. Tuchin ${ }^{11,13,24,25}$

${ }^{1}$ Institute of Electronics, Bulgarian Academy of Sciences, Sofia, Bulgaria

${ }^{2}$ Institute of Organic Chemistry with Centre of Phytochemistry, Bulgarian Academy of Sciences, Sofia, Bulgaria

${ }^{3}$ Tsaritsa Yoanna-ISUL University Hospital, Sofia, Bulgaria

${ }^{4}$ Technical University Sofia, Branch Plovdiv, Plovdiv, Bulgaria

${ }^{5}$ LPICM, CNRS, Ecole Polytechnique, Institut Polytechnique de Paris, Palaiseau, France

${ }^{6}$ Research and Development Center of Biomedical Photonics, Orel State University, Orel, Russia

${ }^{7}$ College of Engineering and Physical Sciences, Aston University, Birmingham, UK

${ }^{8}$ Optoelectronics and Measurement Techniques Unit, University of Oulu, Oulu, Finland

${ }^{9}$ Institute of Clinical Medicine N.V. Sklifosovsky, I.M. Sechenov First Moscow State Medical University, Moscow, Russia

${ }^{10}$ Department of Laser and Biotechnical Systems, Samara National Research University, Samara, Russia

${ }^{11}$ Science Medical Center, Saratov State University, Saratov, Russia

12 Physics Department, Humboldt University, Berlin, Germany

${ }^{13}$ Laboratory of Laser Molecular Imaging and Machine Learning, National Research Tomsk State University, Tomsk, Russia

${ }^{14}$ Saratov State Medical University, Saratov, Russia

${ }^{15}$ Biophotonics Laboratory, Institute of Atomic Physics and Spectroscopy, University of Latvia, Riga, Latvia

${ }^{16}$ Department of Biophysics, Manipal School of Life Sciences, Manipal Academy of Higher Education, Manipal, Karnataka, India

${ }^{17}$ Department of Cell and Molecular Biology, Manipal School of Life Sciences, Manipal Academy of Higher Education, Manipal, Karnataka, India

18 University of Sussex, UK

${ }^{19}$ Physics Department, School of Engineering, Polytechnic Institute of Porto, Porto, Portugal

${ }^{20}$ Center of Innovation in Engineering and Industrial Technology, ISEP, Porto, Portugal

${ }^{21}$ Faculty of Physics, M.V. Lomonosov Moscow State University, Moscow, Russia

${ }^{22}$ Department of Biomedical Engineering and Physics of the Academic Medical Centre in Amsterdam, Amsterdam, the Netherlands

${ }^{23}$ Surgical Innovations Group at the Netherlands Cancer Institute, Amsterdam, the Netherlands

${ }^{24}$ Laboratory of Laser Diagnostics of Technical and Living Systems, Precision Mechanics and Control Institute of the Russian Academy of Sciences, Saratov, Russia 
${ }^{25}$ A.N. Bach Institute of Biochemistry, Research Center of Biotechnology of the Russian Academy of Sciences, Moscow, Russia

*e-mail: ts.genova@gmail.com

\section{Introduction}

Regretfully, because of her sudden demise, Assoc. Prof. Ekaterina Borisova is no longer amongst us. COVID-19 pulled away a brilliant scientist during the peak of her scientific career (see Fig. 1). All authors would like to express deepest condolences and sincere support to her family, friends, relatives and colleagues! We, therefore, rightfully commemorate her dedicated and devoted contribution to biophotonics, her readiness to always support, help, motivate and inspire all her colleagues and collaborators.

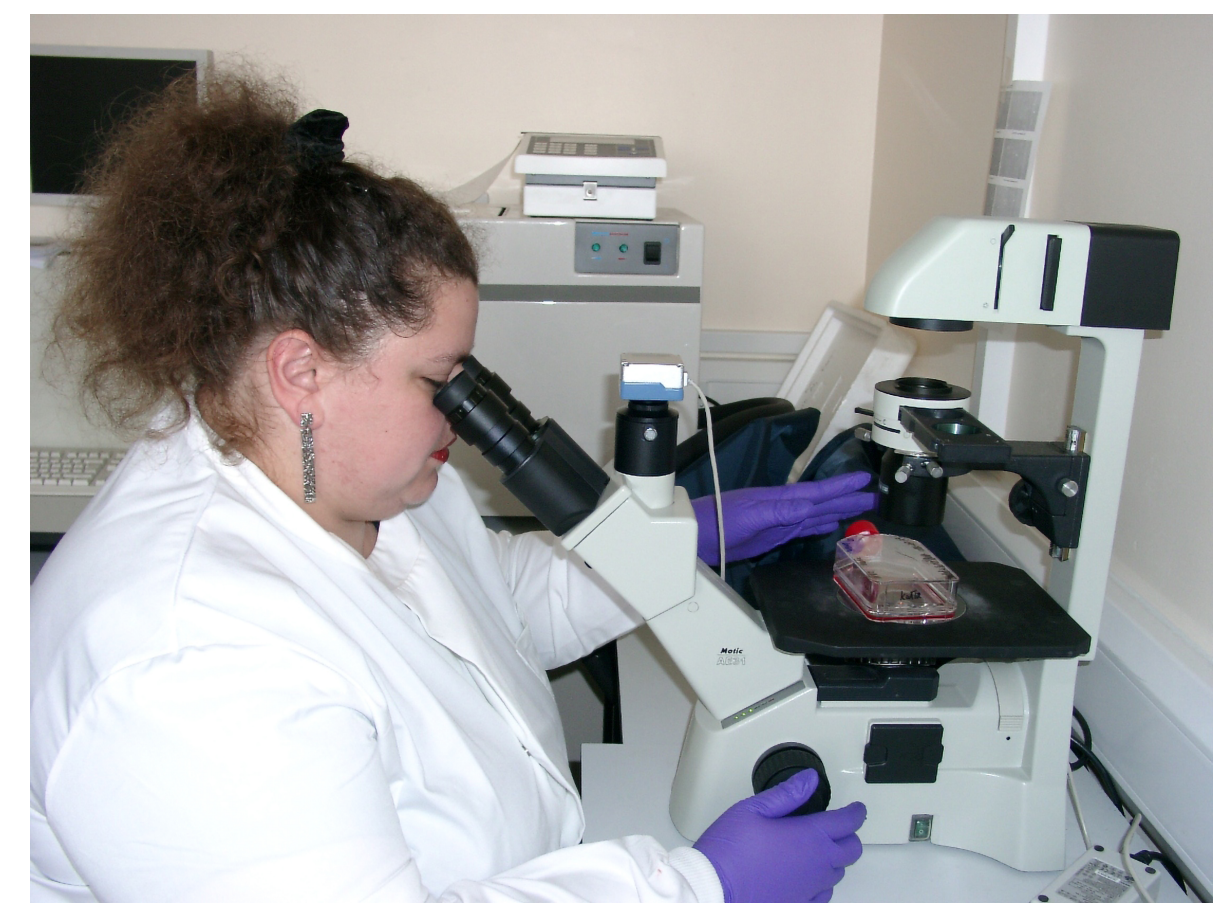

Fig. 1 Assoc. Prof. Ekaterina Borisova examining samples under microscope.

\section{Biography}

Ekaterina Borisova was an alumna in Medical Physics and Laser Physics from Faculty of Physics, Sofia University, Bulgaria. Her PhD degree in Physics was obtained from the Institute of Electronics Bulgarian Academy of Sciences (IE-BAS) in 2005. At the age of 29 she was one of the youngest researchers in Bulgaria to reach the academic position of Associate Professor. In 2012 she became a Scientific Secretary of IE-BAS, in 2014 - Member of the Academic Council in the BAS and in March 2016 she was elected as a member of the Executive Council of the BAS. She has a great publication impact as author/co-author of six book chapters, more than 120 articles in peer-review journals and full texts conference reports, five national and European patents in the field of biophotonics. 
Assoc. Prof. Ekaterina Borisova's scientific contribution was recognized with senior membership of SPIE (2015), SPIE community champion award (2021). She was also the member of the European Physics Society, European Society of Photobiology, European Platform of Photodynamic Medicine and Union of Physicists in Bulgaria. In 2019 she was elected to the class of OSA Senior members. The research of Assoc. Prof. Ekaterina Borisova in the field of optical spectroscopy of human tissues for oncologic applications was honored with the BAS Prize for best young scientist in the field of Physics (2004), Prize "Pythagoras" of the Ministry of Education and Sciences for the Best Young Scientist in Bulgaria in the year 2012. She was one of the winners to receive an UNESCO / L'Oreal fellowship "For Women in Science" for Bulgaria in 2014.

Her professionalism and devotion to science was recognized with inclusion in the editorial board of the Journal of Biomedical Photonics \& Engineering. A large amount of the duly efforts of Dr. Ekaterina Borisova were focused on the clinical implementation of spectroscopy methods for cancer detection, so called optical biopsy in the University Hospital "Tsaritsa Yoanna - ISUL", Sofia, Bulgaria. She started and took an active part in the foundations of the Biophotonics laboratory and the National Center of Biomedical photonics in the Institute of Electronics, Bulgarian Academy of Sciences. Assoc. Prof. Borisova was a supervisor of numerous undergraduate students who finished their academic education and many of them pursued a carrier of researchers with her guidance and support.

\section{Scope of Research}

The primary scientific topic of Assoc. Prof. Ekaterina Borisova was the optical techniques for diagnostics and development of laser and optical systems for biomedical and clinical application. The scope of her research included fluorescence and diffuse optical spectroscopy (DOS), application of novel photosensitizers and photodiagnosis, photodynamic therapy, opening of the blood brain-barrier, Raman spectroscopy of biological tissues, photoinactivation of pathogens, application of polarized light techniques in fluorescence spectroscopy and in tissue polarimetry for cancer detection.

\subsection{Skin optical biopsy}

In the last 10 years she worked persistently on one of her ultimate research goals - the development of a clinical device for objective diagnosis of cutaneous lesions. Her pioneering work was focused on detailed investigations of the fluorescence and DOS optical properties of skin ex vivo and in vivo [1-22]. The main fluorophores and chromophores, as well as their diagnostic value for differentiation of skin lesions versus normal tissue have been evaluated [23, 24]. The applicability of different approaches for data processing was also investigated [25-28]. From then on, she had been patiently gathering spectral data for the development of a robust algorithm for tissue classification [26, 28]. These studies resulted in the creation of a prototype device for diagnosis of cutaneous lesions that goes now through the clinical trials stage. She further focused on optical biopsy of skin with the study of new 
optical modalities and combinations of complementary techniques for the diagnosis of pathological tissue alterations [29-35].

A cooperative work between Assoc. Prof. Ekaterina Borisova and Prof. Petya Pavlova from Technical University Sofia, branch Plovdiv, started in 2004, when significant efforts were spent to find suitable method for automated classification of skin diseases using spectra and extracting some etalon distributions. The first result was presented at IX national conference of "Biomedical physics and engineering", Sofia, 2004. Assoc. Prof. Ekaterina Borisova showed a part of this work at Conference on Lasers and Electro-Optics Europe (2007) [25]. Non-traditional techniques were used for testing similarity by applying mathematical transformations from colorimetry. This method provided options to connect the spectrums with the digital images of lesions. The results were presented at XVII International Laser Physics Workshop, (LPHYS'09) in Barcelona [19] and were included in the specialized book "Melanoma in the Clinic - Diagnostics, Management and Complications of Malignancy" [36]. We also tried to involve scientists from other areas expanding the comparative analysis with use of neural networks and presenting the results at technical conference of IFAC "Technology, culture and international stability" [28].

Assoc. Prof. Ekaterina Borisova was always ready to embrace new ideas and scientific horizons, for instance, by adopting multimodal techniques, including multispectral, fluorescence lifetime and Raman imaging/spectroscopy for skin diagnosis/analysis [37-38] and autofluorescence spectroscopy of cutaneous neoplasia under different spectral domain excitation wavelengths [39].

\subsection{Autofluorescence and photodiagnosis, photodynamic therapy of gastrointestinal tract}

Assoc. Prof. Ekaterina Borisova was also directing her efforts to the improvement of gastrointestinal cancer diagnostics by using endogenous and exogenous fluorescence imaging and spectroscopy. A detailed study on the endogenous fluorophores in the lower part of the gastrointestinal tract investigated with the fluorescence spectroscopy was carried out in the framework of this topic [40-42]. The implementation of a novel technique for tissue investigation - synchronous fluorescence spectroscopy, resulted in better addressing of the endogenous fluorophores observed in tissues [43-46]. The biological origin of the fluorescence contrast between cancerous and healthy gastrointestinal tissue was one of the main investigated areas [47], to determine more sensitive and specific optical markers for tissue differentiation and early detection of gastrointestinal cancer with autofluorescence diagnostics.

Moreover, Assoc. Prof. Ekaterina Borisova also worked on photodiagnosis and photodynamic therapy of gastrointestinal tract. Her work included the investigation of novel photosensitizers and the optimal parameters for their irradiation and photodynamic activation [48-57]. As a result, significant amount of her work was dedicated to the photodynamic diagnosis $[48,58]$, photodynamic efficacy [59] and therapy as well [60-63]. 


\subsection{Photodynamic opening of blood-brain barrier}

Another significant scientific scope of research was extensively studied by Assoc. Prof. Ekaterina Borisova and colleagues - the photodynamic opening of the blood-brain barrier [64] and evaluation of pathways for brain clearing [65], also including the use of different photosensitizers [66], optimizing laser technologies for targeted opening of the blood-brain barrier and targeted drug brain delivery $[67,68]$.

\subsection{Polarization-sensitive optical techniques}

Additionally, polarized light-based techniques were also implemented as label-free diagnostic modalities for biomedical applications. Firstly, the polarization effects in autofluorescence spectra were reported [69], later on this work was extended to obtain polarization sensitive excitation-emission matrices for colorectal tumor detection [70]. In 2017 an international scientific "POLHIS" project was initiated with the LPICM, Ecole Polytechnique, France, for digital histology of tissues with Mueller matrix microscopy. Thereafter, the polarimetric diagnosis of tissues became a focus of another cooperation with the Institute of Optical Materials and Technologies, "Acad. J. Malinowski" Bulgarian Academy of Sciences, yielding several proceedings papers [71-73], one of which was recognized with Best Student Paper Award from the SPIE [74]. Further, a memorandum for cooperation between the IE-BAS and the University of Oulu, Finland, was useful to produce other prolific results in the field of tissue polarimetry [75-77], where one of the manuscripts was awarded with a Cover Page in the Journal of Biophotonics [75]. A currently ongoing project between the IE-BAS and the Department of Biophysics from Manipal School of Life Sciences and Manipal Academy of Higher Education, India, has also demonstrated the important scientific findings on polarimetric detection of the malignant lesions of the digestive system [78] within the framework of the Machine-Learning approach [79]. Also, a review article is submitted and entitled as "Types of spectroscopy and microscopy techniques for cancer diagnosis: a review" to Lasers in Medical Sciences [80]. In memory of Assoc. Prof. Ekaterina Borisova, we are editing a book entitled "Optical Polarimetric Modalities for Biomedical Research" in Springer-Nature [81].

\subsection{Modelling and Monte Carlo simulations}

During the last few years, in a collaboration with Prof. Igor Meglinski (Oulu, Finland) and Dr. Tatiana Novikova (CRNS, France), Assoc. Prof. Ekaterina Borisova expressed her interest to their pioneering studies dedicated to propagation of cylindrical vector laser beams through turbid tissue-like scattering medium [82-84]. Assoc. Prof. Ekaterina Borisova provided tissue samples to the team and, therefore, the ground-breaking experiments of transferring shaped light carrying orbital angular momentum through the cancerous and non-cancerous tissues [84-86] became possible. Thus, with Katia's input we expect further revolutionary developments in Biomedical Optics and Biophotonics with so-called twisted light. 


\section{Prolific international collaborations}

For many years, together with Alexander Priezzhev and Valery Tuchin, Assoc. Prof. Ekaterina Borisova led the Biophotonics section at the world-famous International Conference Laser Optics (ICLO) in St. Petersburg, was the editor of special issues of the world's leading journals in the field of biophotonics and biomedical optics, collaborated with many scientific groups, including several groups at Saratov State University (in addition to the already mentioned joint publications see more [65, 68, 87-98]), Moscow State University and the Polytechnic of Porto.

In a very prolific way, Ekaterina Borisova had been successfully gathering scientists from different countries and institutions to work together. Recently, in Saratov through the efforts of the Institute of Electronics, Bulgarian Academy of Sciences, together with SSU, SSMU, Institute of Biochemistry and Physiology of Plants and Microorganisms and Precision Mechanics and Control Institute of the Russian Academy of Sciences, the development of a new strategy for the combined treatment of a tumor has begun, namely, the plasmon photothermal and photodynamic anticancer therapies using nanocomposites of gold nanoparticles with a novel type photosensitizer. The first results showed the effectiveness of the approach [98], but unfortunately, they were suspended. Ekaterina was the link between scientific groups from Bulgaria and Russia that synthesized agents and nanocomposites and conducted animal tests. For all of us, the loss of Assoc. Prof. Ekaterina Borisova is very painful. We hope to be able to continue research in memory of her.

Furthermore, Ekaterina Borisova had good collaboration with many Russian groups. During 3 years she has joint projects with Oxana Semyachkina-Glushkovskaya's team in Saratov State University. Assoc. Prof. Ekaterina Borisova was PI of the project from Russian Foundation of Basic Research (2017-2018) "Development of new optical technologies for improvement of diagnostics quality of gastric cancer". The aim of the project was to develop innovative technologies for sensitive diagnosis of the initial stages of gastric cancer and ways to prevent the development of metastases, as well as preventive methods to reduce the incidence of this pathology in risk groups. In 2021, Ekaterina received the grant from Russian Science Foundation. The idea of this project was to develop the specific antibodies for fluorescent gastroscopy and detection of malignant changes in stomach. Assoc. Prof. Ekaterina Borisova was also co-PI of project "Development of a pilot technology for early diagnosis of gastric cancer based on fluorescent gastroscopy using immune antibodies to PD-L1“. The project solves the urgent and complex problem of early diagnosis of gastric cancer based on the application of pioneering discoveries in the field of immunology of malignant tumors and the development of a new direction in the molecular diagnosis of cancer based on the use of antibodies to PD-L1 - the ligand of programmed death. Russian-Bulgarian collaboration was very productive, including organization of exchange of students, training courses and publication more than 30 articles in the peer review journals (see Refs. [64-68, 87-99]) as well as preparation of several thesis of candidate of science. She kindly allowed us to publish for the first time the maps of autofluorescence emission of normal skin in vivo measured by her in the monograph (Fig. 5.5) [93] and was very proud 
about that. The ideas of Ekaterina will be continued in further research at Saratov State University with the sunny memory about the best friend and bright scientist.

In 2019, Luís Oliveira invited Ekaterina Borisova and Irina Larina from the Baylor College of Medicine in Texas, USA, to organize a biophotonics session in the PHOTOPTICS conference, which was held in Malta on February 2020 [100]. Although COVID-19 was starting to spread by that time, their joint efforts brought many worldwide known speakers to Malta to participate in this session, turning it a success. Also, in mid-2019, Ekaterina Borisova invited Luís Oliveira, so that they could both serve as co-editors of a special issue of the Journal Electronics (MDPI), with the title "Advanced Laser Technologies for Biophotonics", which was open for submissions until June 2021 [102].

Another close collaboration between Assoc. Prof. Ekaterina Borisova and Samara National Research University started in 2019 with a joint project "Multivariative Raman and fluorescence diagnosis of cutaneous tumors". Within this project, scientists from Sofia and Samara tried to combine optical techniques in order to increase the efficiency of skin cancer diagnosis. This collaboration provided an opportunity to perform joint studies of ex vivo tumors [102] and analyze the in vivo data collected both in Sofia and Samara [32], including data that helped to detect such rare tumor as amelanotic melanoma [103]. During her short visit to Samara (November 2019) Assoc. Prof. Ekaterina Borisova presented a number of lectures in Samara State Medical University and in Samara National Research University devoted to fluorescent diagnosis of tumors. One of Ekaterina's lectures was prepared for the junior scientists in the course of XVII Conference on optics and laser physics (run by Samara branch of Lebedev Physical institute of RAS). Collaborators from Sofia and Samara have extensive plans to continue the joint research and experimental work together.

Over the last decade, a number of Assoc. Prof. Ekaterina Borisova's activities involved collaboration with researchers of the Biophotonics Laboratory at University of Latvia led by J. Spigulis. After meetings and discussions at several international conferences (including SFM-2012 in Saratov), Ekaterina's PhD student Alexandra Zhelyazkova participated at the first BiophotonicsRiga conference in August 2013. Good working contacts were established, and next year both Bulgarian ladies came to Riga, this time to the AOMD-8 conference where Ekaterina Borisova presented an invited talk [27]. This conference involved also a working group's meeting of the COST BM1205 action "European network for skin cancer detection using laser imaging" where both Riga and Sofia groups were represented. Regular meetings of this action took place at various European cities (Brussels, Leeds, Sheffield, Floriana, Amsterdam, Porto, Split, Angers, Bari), which made possible to meet Assoc. Prof. Ekaterina Borisova several times a year and to exchange the latest research news of Riga and Sofia groups. Personal exchanges have started (Alexandra to Riga and Dr. Ilona Kuzmina to Sofia) which resulted in a joint paper [29] presented in Ekaterina's invited talk at the Biophotonics Riga - 2017 conference. The next, maybe most important step in our collaboration was the joint Bulgarian-Latvian research project "Multispectral and fluorescent imaging of skin tumours" initiated by Katia late 2017 in the frame of collaboration agreement between Bulgarian and Latvian Academies of Sciences. It included personal exchanges, so opening a 
possibility for J. Spigulis to present results of the Riga group at the ICSQE-20 conference in Nessebar [104] and to visit Katia's lab in September 2018. In summer 2019 two researchers from Riga (I. Lihacova and A. Lihacev) visited the colleagues in Sofia, and Katia paid a return visit to Riga in frame of this project in November 2019. Soon after that her student Deyan Ivanov visited Riga where joint measurements of the ex vivo skin lesion samples (brought from Sofia) were taken; the results were reported in the SPIE BIOS'2020 conference [37]. After the Covid-19 pandemic started in March 2020, only virtual meetings were allowed; two of them included the Ekaterina's invited talk at the Biophotonics Riga - 2020 conference in August [33] and the invited talk of J. Spigulis at the ICSQE-21 conference [105] in September, 2020. Assoc. Prof. Ekaterina Borisova chaired the virtual session in this conference, full of optimism as usually.

"I have always admired Katia's energy and optimism, as well as the fact that the difficult position in which she had to compete with the rest of the world did not stop her from doing it anyway," writes Dick Sterenborg from the Academic Medical Centre in Amsterdam and the Netherlands Cancer Institute. At her invitation, I twice traveled to Nessebar, next to the Burgas, Bulgaria, where she created a pleasant and comfortable atmosphere at the conference, and together we tried to get a grant, but it never came to real cooperation, her passing away prevented.

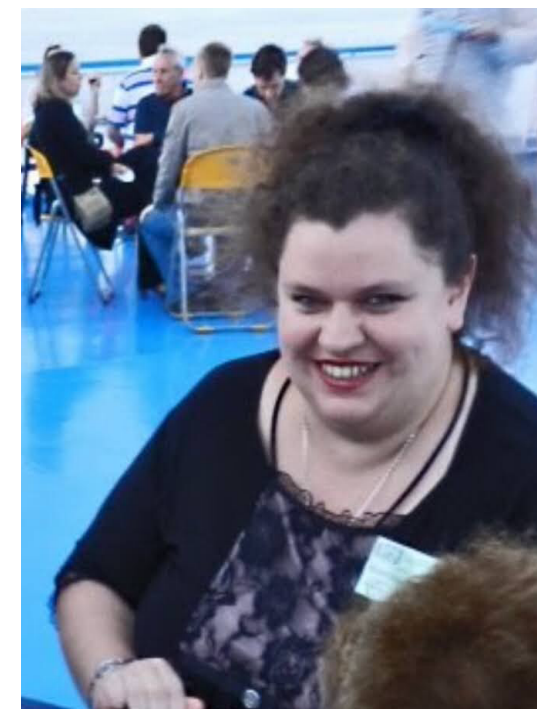

Fig. 2 Assoc. Prof. Ekaterina Borisova at the VII International Symposium "TOPICAL PROBLEMS

OF BIOPHOTONICS - 2019" (TPB-2019) held on board of a river ship cruising along the Volga river (Russia) from July 27 through July 31, 2019, organized by the Institute of Applied Physics of the Russian Academy of Sciences and the Privolzhskiy Research Medical University as a continuation of the previous TPB symposia held biannually from 2007 through 2017 that attracted leading experts in the field of biophotonics from around the world.

Ekaterina Borisova's capability to organize and host scientific events has resulted in the completion of numerous international meetings in Bulgaria and all over the world. She gained experience in hosting international scientific events being the chair of the $15^{\text {th }}$ International School on Quantum Electronics which took place from 15 to 19 September 2008 in Bourgas, Bulgaria, established by Institute of Electronics, Bulgarian Academy of Sciences [106]. For the $23^{\text {th }}$ Annual International Laser Physics Workshop (LPHYS'14) held from July 14 to July 18, 2014 in the city of 
Sofia, Bulgaria [107] and hosted by IE-BAS Assoc. Prof. Ekaterina Borisova was leading the local organizing committee. She was in Advisory \& Program Committee of the 26th Annual International Laser Physics Workshop [108]. In 2010, she won the invitation to hold in Bulgaria in 2011 the $19^{\text {th }}$ meeting of the famous annual International Conference on Advanced Laser Technologies (ALT'11). Her brilliantly prepared proposal successfully competed with that prepared by the Italian colleagues. The ALT'11 meeting was held in Golden Sands resort from 3 to 8 September 2011. On institutional level, it was co-organized by the Institute of Electronics, Bulgarian Academy of Sciences; Prokhorov General Physics Institute, Russian Academy of Sciences; International Laser Center of M.V. Lomonosov Moscow State University and the Center for Laser Technology and Materials, Russian Academy of Sciences. As the Chair-person of the local organizing committee Ekaterina Borisova succeeded in holding a very successful conference. According to general opinion of the participants (see photo in Fig. 3) the ALT'11 meeting was among the best ones held in previous years. Selected papers presented at the conference were published in the Special Section on Laser Technologies for Biomedical Applications of the high-ranking Journal of Biomedical Optics [109].

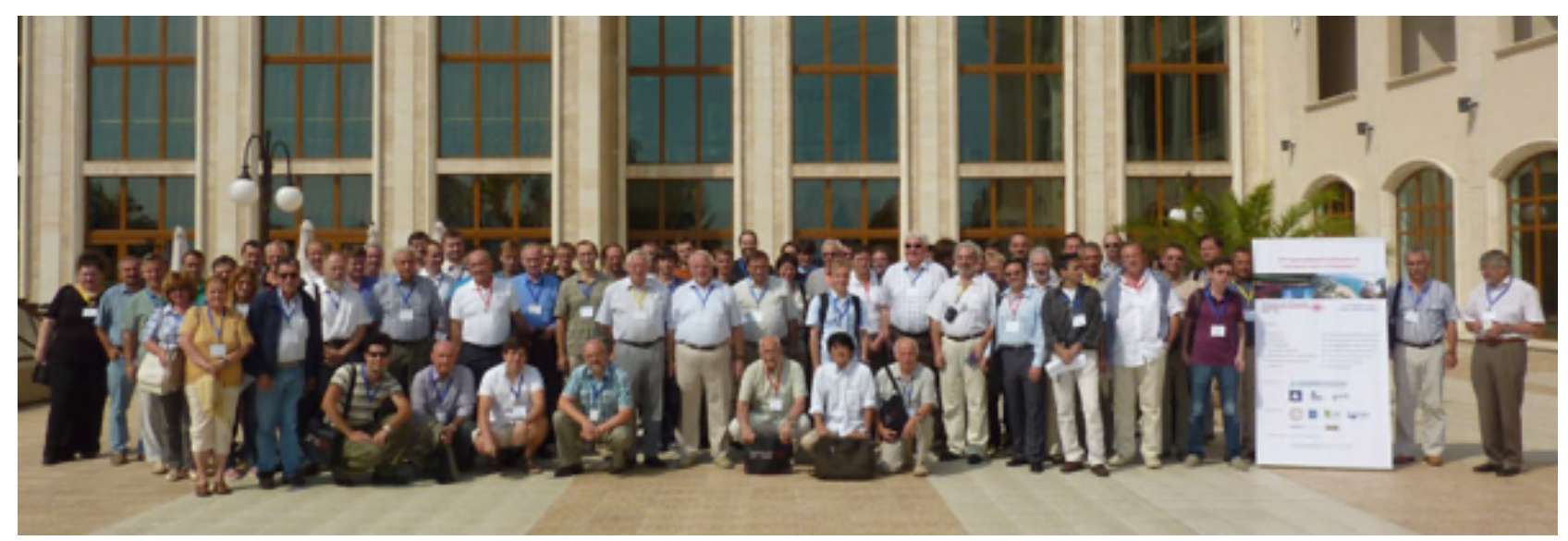

Fig. 3 Group photo of attendees of the ALT'11 meeting (Golden Sands resort, Bulgaria, from 3 to 8 September 2011), organized by Ekaterina Borisova (first on the left).

\section{Conclusion}

In a recent interview to the OSA journal Optics \& Photonics News [110] Assoc. Prof. Ekaterina Borisova said: "I am already the head of the "Biophotonics" laboratory at the IE-BAS. I do have a plenty of research plans - to raise the number of optical spectroscopic techniques and instruments that we use now for biological tissue investigations; to train new junior scientists and students in the field of biophotonics; to work for an enlargement of the role of spectroscopic techniques for early detection of cancer as primary and add-on tools in clinical diagnostics." Those words embodied her lively plans for the future, a future she was robbed of.

All those who had the privilege to know, study, work and interact with Assoc. Prof. Ekaterina Borisova feel the immense pain of the huge loss imposed, hence, being deprived of a wonderful colleague, teacher, leader, supervisor, friend with smart sense of humor and competency in all aspects of life, prolific scientist, bright and unique person (see Fig. 2). Assoc. Prof. Ekaterina Borisova's 
great legacy is to continue the work on her ideas, reach the goals she had set and follow her inspiration.

We are grateful for the given opportunity to knew Katia, to work with her and to be her friends! You will stay always in our hearts, Katia...

\section{Acknowledgements}

We would like to acknowledge the support from the National Science Fund of the Bulgarian Ministry of Education and Science (NSFB-MES) under all current projects involving Assoc. Prof. Ekaterina Borisova, which are grant numbers: \#DN 18-8; \#KP06-N29/11/18.12.18; \#KP06-N28/11/14.12.2018; \#KP06-Russia-9/2020; \#KP-06-N23/8; \#KP-06/N38/13; \#KP06-India-8/07.08.2019; \#KP-06-KOST-6. Also, projects under NRRI \#DO1-401/18.12.2020 and \#D01-392/18.12.2020.

\section{References}

1. E. G. Borisova, L. A. Avramov, "Laser system for optical biopsy and in vivo study of the human skin," Proceedings of SPIE 4397, 405-409 (2001).

2. P. Djorev, E. Borisova, and L. Avramov, "Interaction of the IR laser radiation with human skin - Monte-Carlo simulation," Proceedings of SPIE 5226, 403-407 (2003).

3. E. G. Borisova, P. P. Troyanova, V. P. Stoyanova, and L. A. Avramov, "Laser-induced fluorescence spectroscopy of benign and malignant cutaneous lesions," Proceedings of SPIE 5830, 394-398 (2005).

4. L. Avramaov, E. Borisova, P. D. Townsend, and L. A. Valberg, "Potential and Current Uses Of Luminescence In Medical Diagnosis," Materials Science Forum 480-481, 411-416 (2005).

5. E. Borisova, I. Angelov, V. Mantareva, D. Petrova, P. Townsend, L. Valberg, and L. Avramov, "Tumour detection by exogenous fluorescent dyes using new generation photomultiplier tubes," Proceedings of SPIE 5830, 399-403 (2005).

6. E. Borisova, P. Trojanova, and L. Avramov, "Reflectance measurements of skin lesions - Noninvasive method for diagnostic evaluation of pigmented neoplasia," Proceedings of SPIE 5862, 58620A (2005).

7. E. Borisova, L. Avramov, and P. Troyanova, "Light-induced fluorescence spectroscopy and optical coherence tomography of basal cell carcinoma," Journal of Innovative Optical Health Sciences 2(03), 261-268 (2009).

8. E. Borisova, P. Troyanova, and L. Avramov, "Optical biopsy of non-melanin pigmented cutaneous benign and malignant lesions," Proceedings of SPIE 6257, 62570U (2006).

9. E. Borisova, I. Bliznakova, N. Momchilov, P. Troyanova, and L. Avramov, "Fluorescence spectroscopy investigations of cutaneous tissues," AIP Conference Proceedings 899, 465-466 (2007).

10. I. Bliznakova, E. Borisova, and L. Avramov, "Laser- and light-induced autofluorescence spectroscopy of human skin in dependence on excitation wavelengths," Acta Physica Polonica A 112(5), 1131-1136 (2007).

11. E. Borisova, I. Bliznakova, P. Troyanova, and L. Avramov, "Light-induced autofluorescence of animal skin used in tissue optical modeling," Optics InfoBase Conference Papers 6628, 60 (2007).

12. E. G. Borisova, E. Nikolova, P. P. Troyanova, and L. A. Avramov, "Autofluorescence and diffuse reflectance spectroscopy of pigment disorders in human skin," Journal of Optoelectronics and Advanced Materials 10(3), 717722 (2008). ISSN: 14544164.

13. P. Troyanova, E. Borisova, and L. Avramov, "Fluorescence and reflectance properties of hemoglobin-pigmented skin disorders," Proceedings of SPIE 6734, 673415 (2007).

14. E. Borisova, P. Troyanova, and L. Avramov, "Influence of measurement geometry on the human skin reflectance spectra detection," Proceedings of SPIE 6734, 673416 (2007).

15. E. Borisova, P. Troyanova, P. Pavlova, and L. Avramov, "Diagnostics of pigmented skin tumors based on laserinduced autofluorescence and diffuse reflectance spectroscopy," Quantum Electronics 38(6), 597-605 (2008).

16. E. Borisova, P. Troyanova, E. Nikolova, and L. Avramov, "Cutaneous tumors in vivo investigations using fluorescence and diffuse reflectance techniques," Proceedings of SPIE 6791, 679105 (2008).

17. E. Borisova, D. Dogandjiiska, I. Bliznakova, L. Avramov, E. Pavlova, and P. Troyanova, "Multispectral autofluorescence diagnosis of non-melanoma cutaneous tumors," Proceedings of SPIE 7368, 736823 (2009).

18. E. Borisova, L. Avramov, P. Pavlova, E. Pavlova, and P. Troyanova, "Qualitative optical evaluation of malignancies related to cutaneous phototype,” Proceedings of SPIE 7563, 75630X (2010). 
19. P. Pavlova, E. Borisova, L. Avramov, E. Petkova, and P. Troyanova, "Investigation of Relations between Skin Cancer Lesions' Images and Their Fluorescent Spectra," Laser Physics 20(3), 596-603 (2010).

20. E. Borisova, P. Pavlova, E. Pavlova, P. Troyanova, and L. Avramov, "Optical biopsy of human skin - A tool for cutaneous tumours' diagnosis," International Journal Bioautomation 16 (1), 53-72 (2012).

21. V. Mantareva, D. Petrova, L. Avramov, I. Angelov, E. Borisova, M. Peeva, and D. Wöhrle, "Long wavelength absorbing cationic $\mathrm{Zn}(\mathrm{II})$-phthalocyanines as fluorescent contrast agents for B16 pigmented melanoma," Journal of Porphyrins and Phthalocyanines 9(1), 47-53 (2005).

22. E. Drakaki, E. Borisova, M. Makropoulou, L. Avramov, A. A. Serafetinides, and I. Angelov, "Laser induced autofluorescence studies of animal skin used in modeling of human cutaneous tissue spectroscopic measurements," Skin Research and Technology 13(4), 350-359 (2007).

23. A. Zhelyazkova, E. Borisova, L. Angelova, E. Pavlova, and M. Keremedchiev "Excitation-emission matrices measurements of human cutaneous lesions - Tool for evaluation of fluorescence origin," Proceedings of SPIE 9032, 90320A (2013).

24. G. Borisova, P. Angelova, and P. Pavlova, "Endogenous and exogenous fluorescence skin cancer diagnostics for clinical applications," IEEE Journal of Selected Topics in Quantum Electronics 20(2), 6606819 (2014).

25. E. Borisova, P. Pavlova, P. Troyanova, and L. Avramov, "Automation of cancer diagnosis based on colorimetric transformation of cutaneous reflectance spectra," Optics InfoBase Conference Papers 4386657, 73192 (2007).

26. E. Borisova, E. Pavlova, T. Kundurjiev, P. Troyanova, T. Genova, and L. Avramov, "Light-induced autofluorescence and diffuse reflectance spectroscopy in clinical diagnosis of skin cancer," Proceedings of SPIE 9129, 912910 (2014).

27. E. Borisova, Al. Jeliazkova, E. Pavlova, P. Troyanova, T. Kundurdjiev, P. Pavlova, and L. Avramov, "Reflectance spectroscopy of pigmented cutaneous benign and malignant lesions," Proceedings of SPIE 9421, 94210I (2014).

28. Pavlova P., N. Shakev, and E. Borisova, "Comparative analysis of methods for ascertainment the similarity between reflected spectra obtained from skin lesions," IFAC PapersOnLine 52(25), 365-369 (2019).

29. E. Borisova, T. Genova, P. Troyanova, I. Terziev, V. Zakharov, I. Bratchenko, M. Lomova, D. Gorin, and L. Avramov, "Microscopic and macroscopic spectral peculiarities of cutaneous tumours," Proceedings of SPIE 10592, 1059202 (2017).

30. E. Borisova, T. Genova-Hristova, P. Troyanova, I. Terziev, E. A. Genina, A. N. Bashkatov, O. SemyachkinaGlushkovskaya, V. Tuchin, and L. Avramov, "Optical UV-VIS-NIR spectroscopy of benign, dysplastic and malignant cutaneous lesions ex vivo," Proceedings of SPIE 10685, 106853T (2018).

31. E. Borisova, T. Genova-Hristova, P. Troyanova, E. Pavlova, I. Terziev, O. Semyachkina-Glushkovskaya, M. Lomova, E. Genina, G. Stanciu, D. Tranca, and L. Avramov, "Multispectral detection of cutaneous lesions using spectroscopy and microscopy approaches," Proceedings of SPIE 10467, 104670M (2018).

32. E. Borisova, A. Gisbrecht, T. Genova-Hristova, P. Troyanova, E. Pavlova, N. Penkov, I. Bratchenko, V. Zakharov, I. Lihachova, I. Kuzmina, and J. Spigulis, "Multispectral autoflourescence detection of skin neoplasia using steadystate techniques," Proceedings of SPIE 11047, 1104704 (2019).

33. E. Borisova, T. Genova, V. Mircheva, P. Troyanova, I. Bratchenko, L. Bratchenko, Y. Khristoforova, V. Zakharov, I. Lihacova, A. Lihacovs, and J. Spigulis, "Multispectral fluorescence detection of pigmented cutaneous tumours," Proceedings of SPIE 11585, 1158504 (2020).

34. Y. A. Khristoforova, I. A. Bratchenko, L. A. Bratchenko, O. O. Myakinin, D. N. Artemyev, A. A. Moryatov, S. V. Kozlov, E. G. Borisova, T. I. Genova, P. P. Troyanova, and V. P. Zakharov, "Optical biopsy of skin cancer based on Raman and fluorescence spectroscopy,” Proceedings of SPIE 11582, 115821K (2020).

35. V. Mircheva, L. Zaharieva, S. Ilyov, P. Troyanova, I. Lihacova, A. Lihacovs, I. Bratchenko, L. Bratchenko, Y. Khristoforova, and V. Zakharov, "Near-infrared autofluorescence spectroscopy and photobleaching detection of melanin-pigmented cutaneous neoplasia," Journal of Physics: Conference Series 1859 (1), 012044 (2021).

36. P. Pavlova, E. Borisova, L. Avramov, E. Petkova, and P. Trotanova, "Investigation of Relations between Skin Cancer Lesions' Images and Their Reflectance and Fluorescent Spectra," Chapter 6 In Melanoma in the Clinic - Diagnostics, Management and Complications of Malignancy, M. Murph (Ed.), InTech Open Access Publisher, 87-104 (2011). ISBN: 978-953-307-571-6.

37. J. Spigulis, I. Kuzmina, V. Lukinsone, M. Tamošiūnas, I. Oshina, L. Ozolina, A. Maslobojeva, M. Kuzminskis, D. Ivanov, and E. Borisova, "Towards combined multispectral, FLIM and Raman imaging for skin diagnostics," Proceedings of SPIE 11232, 112320N (2020).

38. L. Bratchenko, E. Abrosimova, S. Stafeev, E. Tupikova, E. Borisova, and I. Bratchenko, “Conventional Raman and surface-enhanced Raman spectroscopy for human skin components analysis," In 2020 International Conference on Information Technology and Nanotechnology (ITNT), 26-29 May, Samara, Russia (2020).

39. E. Borisova, D. Ivanov, B. Kolev, T. Genova, V. Mircheva, S. Ilyov, L. Zaharieva, I. Lihachova, A. Lihachovs, J. Spigulis, and P. Troyanova, "Autofluorescence spectroscopy of cutaneous neoplasia under ultraviolet, visible and near infrared excitation,” Proceedings of SPIE 11363, 113630Z (2020).

40. E. Borisova, L. Plamenova, M. Keremedchiev, B. Vladimirov, and L. Avramov, "Endogenous and exogenous fluorescence of gastrointestinal tumors-initial clinical observations," Proceedings of SPIE 8770, 87701C (2013). 
41. E. Borisova, L. Angelova, A. Zhelyakova, T. Genova, O. Semyachkina-Glushkovskaya, M. Keremedchiev, N. Penkov, B. Vladimirov, and L. Avramov, "Endogenous and exogenous fluorescence spectroscopy of gastrointestinal tumours - In vitro studies," Journal of Optoelectronics and Advanced Materials 16(9-10), 1196-1205 (2014). ISSN: 1454-4164.

42. E. Borisova, Ts. Genova, O. Semyachkina-Glushkovskaya, N. Penkov, I. Terziev, and B. Vladimirov, "Excitationemission matrices (EEMs) of colorectal tumors - tool for spectroscopic diagnostics of gastrointestinal neoplasia," Frontiers of Optoelectronics 10(3), 292-298 (2017).

43. E. Borisova, T. Genova, A. Zhelyazkova, L. Angelova, M. Keremedchiev, N. Penkov, I. Terziev, B. Vladimirov, O. Semyachkina-Glukhovskaya, and L. Avramov, "Synchronous autofluorescence spectroscopy of gastrointestinal tumours - Tool for endogenous fluorophores evaluation," Optoelectronics and Advanced Materials, Rapid Communications 9(9-10), 1234-1238 (2015).

44. T. Genova, E. Borisova, A. Zhelyazkova, N. Penkov, B. Vladimirov, I. Terziev, O. Semyachkina-Glushkovskaya, and L. Avramov, "Colorectal cancer stage evaluation using synchronous fluorescence spectroscopy technique," Optical and Quantum Electronics 48(8), 378 (2016).

45. E. Borisova, O. Semyachkina-Glushkovskaya, T. Genova, N. Penkov, I. Terziev, B. Vladimirov, and L. Avramov, "Synchronous fluorescence spectroscopy of colon neoplasia," Proceedings of SPIE 10336, 1033602 (2017).

46. E. Borisova, T. Genova-Hristova, N. Penkov, I. Terziev, P. Troyanova, B. Vladimirov, and L. Avramov, "Synchronous fluorescence spectroscopy of soft tissues - Tool for diagnostics of malignant lesions," Proceedings of 2018 International Conference Laser Optics 8435383, 493 (2018).

47. T. Genova, E. Borisova, N. Penkov, B. Vladimirov, A. Zhelyazkova, and L. Avramov, "Excitation-emission matrices and synchronous fluorescence spectroscopy for cancer diagnostics in gastrointestinal tract," Quantum Electronics 46(6), 510-514 (2016).

48. E. Borisova, O. Semyachkina-Glushkovskaya, N. Navolokin, V. Mantareva, I. Angelov, I. Agranovich, A. Khorovodov, N. Shushunova, A. Bodrova, I. Fedosov, A. Namykin, A. Abdurashitov, and L. Avramov, "Photodynamic diagnostics of stress-induced gastrointestinal neoplasia in laboratory animals using 5-Aminolevulinic acid and Al-phthalocyanine," Proceedings of SPIE 10501, 105011E (2018).

49. I. Agranovich, A. Khorovodov, M. Kanevsky, T. Genova-Hristova, A. Gisbrecht, I. Angelov, V. Mantareva, N. Navolokin, O. Semyachkina-Glushkovskaya, and E. Borisova, "Detection of stress-induced gastrointestinal lesions using Al-phythalocynanines in experimental animals," Proceedings of SPIE 11047, 1104709 (2019).

50. T. Genova, A. Khorovodov, A. Terskov, M. Kanevsky, A. Gisbrecht, L. Avramov, and O. SemyachkinaGlushkovskaya, "Stomach and intestine neoplasia fluorescence detection using 5-ALA/PpIX photosensitization," Proceedings of SPIE 11047, 1104708 (2019).

51. E. Borisova, T. Genova, A. Khorovodov, I. Agranovich, M. Kanevskiy, S. Konnova, I. Angelov, V. Mantareva, N. Navolokin, and O. Semyachkina-Glushkovskaya, "ALA/PpIX photodiagnosis of stress-induced gastrointestinal primary tumors and metastases in experimental animals," Proceedings of SPIE 11079, 110790N (2019).

52. I. Agranovich, E. Borisova, N. Navolokin, A. Bucharskaya, G. Maslyakova, A. Shirokov, A. Abdurashitov, I. Angelov, A. Khorovodov, A. Terskov, A. Mamedova, M. Klimova, and O. Semyachkina-Glushkovskaya, "Phenomenon of atypical vascular effects of epinephrine and an increase of photodynamic response by nitroglycerin in rats with colon adenocarcinoma: adrenergic and nitrergic mechanisms and novel applied aspects," Biomedical Optics Express 10(8), 4115-4125 (2019).

53. E. Borisova, T. Genova, A. Yakimansky, V. Mantareva, I. Angelov, A. Gisbrecht, Al. Khorovodov, I. Agranovich, M. Klimova, and O. Semyachkina-Glushkovskaya, "Conjugation of Zn (II) phthalocyanine with polymeric brushes for improved photodiagnostics and photodynamic therapy of gastric tumours," Proceedings of SPIE 11457, 114570R (2020).

54. E. Borisova, M. Kanevskiy, S. Konnova, A. Khorovodov, I. Agranovich, T. Genova, L. Avramov, N. Navolokin, and O. Semyachkina-Glushkovskaya, "5-ALA/PpIX photodiagnosis of stress-induced gastrointestinal metastatic tumours in laboratorial animals," Proceedings of SPIE 11363, 113630U (2020).

55. I. Agranovich, A. Khorovodov, M. Kanevsky, T. Genova, A. Gisbrecht, I. Angelov, V. Mantareva, N. Navolokin, O. Semyachkina-Glushkovskaya, and E. Borisova, "Stress-induced neoplasia detection in the lower part of gastrointestinal tract of rats using phthalocyanines," Journal of Physics: Conference Series 1859(1), 012038 (2021).

56. V. Mantareva, V. Kussovski, I. Angelov, E. Borisova, L. Avramov, G. Schnurpfeil, and D. Wöhrle, "Photodynamic activity of water-soluble phthalocyanine zinc(II) complexes against pathogenic microorganisms," Bioorganic \& Medicinal Chemistry 15(14), 4829-4835 (2007).

57. V. Kussovski, V. Mantareva, I. Angelov, P. Orozova, D. Wöhrle, G. Schnurpfeil, E. Borisova, and L. Avramov, "Photodynamic inactivation of aeromonas hydrophila by cationic phthalocyanines with different hydrophobicity," FEMS Microbiology Letters 294(2), 133-140 (2009).

58. A. Pavlov, E. Borisova, O. Pavlova, I. Agranovich, A. Khorovodov, A. Terskov, A. Mamedova, M. Klimova, L. Avramov, and O. Semyachkina-Glushkovskaya, "Photodynamic diagnostics of early gastric cancer: Complexity measures of gastric microcirculation and new model of metastatic adenocarcinoma of rat stomach," Journal of Innovative Optical Health Sciences 12(2), 1950007 (2019). 
59. V. Mantareva, A. Kril, I. Angelov, R. Dimitrov, E. Borisova, and L. Avramov, "Effects of the position of galactose units to $\mathrm{Zn}(\mathrm{II})$ phthalocyanine on the uptake and photodynamic activity towards breast cancer cells," Proceedings of SPIE 8427, 842743 (2012).

60. I. Angelov, V. Mantareva, V. Kussovski, D. Woehrle, E. Borisova, and L. Avramov, "Improved antimicrobial therapy with cationic tetra- and octa-substituted phthalocyanines," Proceedings of SPIE 7027, 702717 (2008).

61. V. N. Mantareva, I. Angelov, D. Wöhrle, E. Borisova, and V. Kussovski, "Metallophthalocyanines for antimicrobial photodynamic therapy," Journal of Porphyrins and Phthalocyanines 17(6-7), 399-416 (2013).

62. N. Momchilov, I. Bliznakova, E. Borisova, P. Troyanova, and L. Avramov, "Development of low-cost photodynamic therapy device,” Acta Physica Polonica Series A 112(5), 1125-1130 (2007).

63. E. Borisova, D. Kyurkchiev, K. Tumangelova-Yuzeir, I. Angelov, T. Genova-Hristova, O. SemyachkinaGlushkovskaya, and K. Minkin, "Evaluation of photodynamic treatment efficiency on glioblastoma cells received from malignant lesions: Initial studies,” Proceedings of SPIE 10716, 1071602 (2017).

64. O. Semyachkina-Glushkovskaya, J. Kurths, E. Borisova, S. Sokolovski, V. Mantareva, I. Angelov, A. Shirokov, N. Navolokin, N. Shushunova, A. Khorovodov, M. Ulanova, M. Sagatova, I. Agranivich, O. Sindeeva, A. Gekalyuk, A. Bodrova, and E. Rafailov, "Photodynamic opening of blood-brain barrier," Biomedical Optics Express 8(11), 50405048 (2017).

65. O. Semyachkina-Glushkovskaya, V. Chehonin, E. Borisova, I. Fedosov, A. Namykin, A. Abdurashitov, A. Shirokov, B. Khlebtsov, Y. Lyubun, N. Navolokin, M. Ulanova, N. Shushunova, A. Khorovodov, I. Agranovich, A. Bodrova, M. Sagatova, A. E. Shareef, E. Saranceva, T. Iskra, M. Dvoryatkina, E. Zhinchenko, O. Sindeeva, V. Tuchin, and J. Kurths, "Photodynamic opening of the blood-brain barrier and pathways of brain clearing," Journal of Biophotonics 11(8), e201700287 (2018).

66. O. Semyachkina-Glushkovskaya, E. Borisova, V. Mantareva, I. Angelov, I. Eneva, A. Terskov, A. Mamedova, A. Shirokov, A. Khorovodov, M. Klimova, I. Agranovich, I. Blokhina, N. Lezhnev, and J. Kurths, "Photodynamic opening of the blood-brain barrier using different photosensitizers in mice," Applied Sciences (Switzerland) 10(11), 33 (2020).

67. O. V. Semyachkina-Glushkovskaya, A. S. Abdurashitov, E. I. Saranceva, E. G. Borisova, A. A. Shirokov, and N. V. Navolokin, "Blood-brain barrier and laser technology for drug brain delivery," Journal of Innovative Optical Health Sciences 10(51), 1730011 (2017).

68. O. V. Semyachkina-Glushkovskaya, E. U. Rafailov, S. G. Sokolovsky, E. G. Borisova, V. Mantareva, I. Angelov, A. Shirokov, N. Navolokin, N. A. Shushunova, A. P. Khorovodov, A. V. Terskov, A. A. Bodrova, M. V. Ulanova, E. Shrif, V. V. Tuchin, and J. Kurths, "The laser technologies of targeted opening of blood-brain barrier for drug brain delivery," Proceedings of 2018 International Conference Laser Optics (ICLO) 8435846, 501 (2018).

69. E. Borisova, L. Angelova, Al. Jeliazkova, Ts. Genova, E. Pavlova, P. Troyanova, and L. Avramov, "Polarization effects in cutaneous autofluorescent spectra," Proceedings of SPIE 9129, 91292G (2014).

70. E. Borisova, T. Genova, A. Zhelyazkova, L. Angelova, M. Keremedchiev, N. Penkov, and L. Avramov, "Polarization sensitive excitation-emission matrices for detection of colorectal tumours - initial investigations," Journal of Physics: Conference Series 594, 012031 (2015).

71. D. Ivanov, E. Borisova, T. Genova, L. Nedelchev, and D. Nazarova, "Tissue polarimetric discrimination analysis of skin and colon histological samples,” AIP Conference Proceedings 2075, 170017 (2019).

72. D. Ivanov, V. Strijkova, L. Nedelchev, D. Nazarova, and E. Borisova, "Visualizing Healthy and Malignant Tissues via Polarized Light Imaging and Chemical Staining," Journal of Physics and Technology 3(1), 14-17 (2019).

73. D. Ivanov, R. Ossikovski, T. Novikova, P. Li, E. Borisova, T. Genova, L. Nedelchev, and D. Nazarova, "Tissue polarimetric study I: In search of reference parameters and depolarizing Mueller matrix model of ex vivo colon samples," Proceedings of SPIE 11075, 1107514 (2019).

74. D. Ivanov, T. Genova-Hristova, E. Borisova, L. Nedelchev, and D. Nazarova, "Multiwavelength polarimetry of gastrointestinal ex vivo tissues for tumor diagnostic improvement," Proceedings of SPIE 11047, 1104707 (2019).

75. D. Ivanov, V. Dremin, A. Bykov, E. Borisova, T. Genova, A. Popov, R. Ossikovski, T. Novikova, and I. Meglinski, "Colon cancer detection by using Poincaré sphere and 2D polarimetric mapping of ex vivo colon samples," Journal of Biophotonics 13(8), e202000082 (2020).

76. D. Ivanov, V. Dremin, E. Borisova, A. Bykov, T. Novikova, I. Meglinski, and R. Ossikovski, "Polarization and depolarization metrics as optical markers in support to histopathology of ex vivo colon tissue," Biomedical Optics Express 12(7), 4560-4572 (2021).

77. D. Ivanov, V. Dremin, E. Borisova, A. Bykov, I. Meglinski, T. Novikova, and R. Ossikovski, "Symmetric decomposition of Mueller matrices reveals a new parametric space for polarimetric assistance in colon cancer histopathology," Proceedings of SPIE 11646, 1164614 (2021).

78. S. Ilyov, D. Ivanov, Ts. Genova, V. Mircheva, L. Zaharieva, B. Kolev, B. Vladimirov, H. Valkov, N. Mazumder, K. Sindhoora, O. Semyachkina-Glushkovskaya, L. Avramov, and E. Borisova, "Reflectance polarization ex vivo measurements of gastrointestinal carcinoma lesions for cancer diagnostics," Journal of Physics: Conference Series 1859, 012041 (2021). 
79. K. M. Sindhoora, K. U. Spandana, D. Ivanov, E. Borisova, U. Raghavendra, S. Rai, S. P. Kabekkodu, K. K. Mahato, and N. Mazumder, "Machine-learning-based classification of Stokes-Mueller polarization images for tissue characterization," Journal of Physics: Conference Series 1859, 012045 (2021).

80. K. M. Sindhoora, Y. Kistenev, E. Borisova, D. Ivanov, O. Zakharova, A. Boyko, D. Vrazhnov, D. Gopal, S. Chakrabarti, S. Prasada K, and N. Mazumder "Types of spectroscopy and microscopy techniques for cancer diagnosis: a review," Lasers in Medical Sciences [to be published].

81. N. Mazumder, Y. Kistenev, E. Borisova and S. Prasada K. (Eds.), "Optical Polarimetric Modalities for Biomedical Research," Springer-Nature [to be published].

82. A. Doronin, N. Vera, J. P. Staforelli, P. Coelho, and I. Meglinski, "Propagation of cylindrical vector laser beams in turbid tissue-like scattering medium,” Photonics 6(2), 56 (2019).

83. A. Doronin, N. Vera, J. Staforelli, T. Novikova, and I. Meglinski, "Perspectives of optical diagnosis with vector light beams," Proceedings of SPIE 10873, 108730K (2019).

84. I. Meglinski, "Spin Angular Momentum of Light in Digital Histopathology," In International Webinar Conference on Lasers, Optics, Photonics \& Sensors (LOPS 2021), 12-13 June, Virtual Conference (2021).

85. I. Meglinski, "Vector Light in Biomedical Diagnosis," Horizons of Optics, Photonics and Emerging Sciences (HOPES), IEEE Webinar series (2020).

86. I. Meglinski, N. Vera, J. P. Staforelli, and A. Doronin, "Twisted structured light for tissue diagnosis," In $8^{\text {th }}$ International Conference on Photonics, Optics and Laser Technology - PHOTOPTICS 2020, 27-29 February, Valletta, Malta (2020).

87. O. Semyachkina-Glushkovskaya, A. Pavlov, J. Kurths, E. Borisova, A. Gisbrecht, O. Sindeeva, A. Abdurashitov, A. Shirokov, N. Navolokin, E. Zinchenko, A. Gekalyuk, M. Ulanova, D. Zhu, Q. Luo, and V. Tuchin, "Optical monitoring of stress-related changes in the brain tissues and vessels associated with hemorrhagic stroke in newborn rats," Biomedical Optics Express 6(10), 4088-4097 (2015).

88. O. Sindeeva, E. Borisova, A. Abdurashitov, E. Zhinchenko, A. Gekalyuk, M. Ulanova, A. E. Sharif, V. Razubaeva, S. Serov, L. Yankovskaya, V. V. Tuchin, and O. Semyachkina-Glushkovskaya, "The stress-related changes in the cerebral blood flow in newborn rats with intracranial hemorrhage: metabolic and endothelial mechanisms," Journal of Biomedical Photonics \& Engineering 1(4), 248-254 (2016).

89. O. Semyachkina-Glushkovskaya, J. Kurths, A. N. Pavlov, E. G. Borisova, A. S. Abdurashitov, D. Zhu, P. Li, Q. Luo, and V. V. Tuchin, "Silent Vascular Catastrophes in the Brain in Term Newborns: Strategies for Optical Imaging," IEEE Journal of Selected Topics in Quantum Electronics 22(3), 88-101 (2016).

90. O. Semyachkina-Glushkovskaya, E. Borisova, A. Namikin, I. Fedosov, A. Abdurashitov, E. Zhinchenko, A. Gekalyuk, M. Ulanova, V. Rezunbaeva, L. Avramov, D. Zhu, Q. Luo, and V. Tuchin, "Hypoxia and Neonatal Haemorrhagic Stroke: Experimental Study of Mechanisms," Advances in Experimental Medicine and Biology 923, Oxygen Transport to Tissue XXXVIII, Springer International Publishing Switzerland, 173-179 (2016).

91. O. Semyachkina-Glushkovskaya, E. Borisova, M. Abakumov, D. Gorin, L. Avramov, I. Fedosov, A. Namykin, A Abdurashitov, A. Serov, A. Pavlov, E. Zinchenko, V. Lychagov, N. Navolokin, A. Shirokov, G. Maslyakova, D. Zhu, Q. Luo, V. Chekhonin, V. Tuchin and J. Kurths, "The Stress and Vascular Catastrophes in Newborn Rats: Mechanisms Preceding and Accompanying the Brain Hemorrhages," Frontiers in Physiology 7, 210 (2016).

92. V. V. Tuchin, E. Borisova, M. Jędrzejewska-Szczerska, M. J. Leahy, F. S. Pavone, J. Popp, and J. Pozo, “A special issue on Biophotonics in Europe," Frontiers of Optoelectronics 10(3), 203-210 (2017).

93. V. V. Tuchin, Tissue Optics: Light Scattering Methods and Instruments for Medical Diagnostics, $3^{\text {rd }}$ ed., SPIE Press, Bellingham, WA (2015).

94. O. Semyachkina-Glushkovskaya, E. Borisova, S. Sokolovski, V. Mantareva, I. Angelov, A. Shirokov, N. Navolokin, N. Shushunova, A. Khorovodov, M. Ulanova, M. Sagatova, I. Agranivich, A. Bodrova, E. Rafailov, and V. Tuchin, "Laser-induced generation of singlet oxygen: new strategies in the treatment of brain tumor," In International Conference on Photonics and Imaging in Biology and Medicine, 26-28 September, Suzhou, China (2017). ISBN: 978-1-943580-35-4.

95. O. Semyachkina-Glushkovskaya, E. U. Rafailov, S. G. Sokolovsky, E. G. Borisova, V. Mantareva, I. Angelov, A. Shirokov, N. Navolokin, N. A. Shushunova, A. P. Khorovodov, A. V. Terskov, A. A. Bodrova, M. V. Ulanova, E. Shrif, V. V. Tuchin, and J. Kurths, "The Laser Technologies of Targeted Opening of Blood-Brain Barrier for Drug Brain Delivery," In IEEE Conference Proceedings: International Conference Laser Optics, 4-8 June, Saint Petersburg, Russia (2018). ISBN: 978-1-5386-3612-1.

96. O. Semyachkina-Glushkovskaya, J. Kurths, E. Borisova, S. Sokolovski, V. Mantareva, I. Angelov, A. Shirokov, N. Navolokin, N. Shushunova, A. Khorovodov, M. Ulanova, M. Sagatova, I. Agranivich, O. Sindeeva, A. Gekalyuk, A. Bodrova, and E. Rafailov, "Photodynamic opening of blood-brain barrier: non-invasive approaches and age differences," In the $26^{\text {th }}$ International Conference on Advanced Laser Technologies, 9-14 September, Tarragona, Spain (2018).

97. A. N. Bashkatov, V. P. Zakharov, A. B. Bucharskaya, E. G. Borisova, Y. A. Khristoforova, E. A. Genina, and V. V. Tuchin, "Malignant Tissue Optical Properties," Chapter 1 in Multimodal Optical Diagnostics of Cancer, V. V. 
Tuchin, J. Popp, and V. Zakharov (Eds.), Springer Nature Switzerland AG, Cham, Switzerland, 3-106 (2020). ISBN 978-3-030-44593-5.

98. O. Semyachkina-Glushkovskaya, D. Postnov, A. Lavrova, I. Fedosov, E. Borisova, V. Nikolenko, T. Penzel, and V. V. Tuchin, "Biophotonic Strategies of Measurement and Stimulation of the Cranial and the Extracranial Lymphatic Drainage Function," IEEE Journal of Selected Topics in Quantum Electronics 27(4), 7400313 (2021).

99. A. Bucharskaya, G. Maslyakova, M. Chekhonatskaya, S. Pakhomy, D. Mudrak, N. Navolokin, G. Terentyuk, E. Borisova, V. Mantareva, I. Angelov, B. Khlebtsov, N. Khlebtsov, V. Genin, A. Bashkatov, E. Genina, and V. Tuchin, "The assessment of tumor vascularization degree for predicting the effectiveness of plasmonic photothermal and photodynamic therapy," Proceedings of SPIE 11845, 1184508 (2021).

100.Photoptics 2020, 8th International Conference on Photonics, Optics and Laser Technology [https://photoptics.scitevents.org/?y=2020].

101.E. Borisova, and L. Oliveira (Eds.), "Special Issue “Advanced Laser Technologies for Biophotonics,” Electronics (2021).

102.E. Borisova, I. Bratchenko, Y. Khristoforova, L. Bratchenko, T. I. Genova, A. I. Gisbrecht, A. A. Moryatov, S. V. Kozlov, P. P. Troyanova, and V. P. Zakharov, "Near-infrared autofluorescence spectroscopy of pigmented benign and malignant skin lesions," Optical Engineering 59(6), 061616 (2020).

103.I. Bratchenko, Y. Khristoforova, L. Bratchenko, A. Moryatov, S. Kozlov, E. Borisova, and V. Zakharov, "Optical Biopsy of Amelanotic Melanoma with Raman and Autofluorescence Spectra Stimulated by $785 \mathrm{~nm}$ Laser Excitation," Journal of Biomedical Photonics \& Engineering 7(2), 020308 (2021).

104.J. Spigulis, A. Lihachev, V. Lukinsone, M. Osis, and I. Oshina, "Lasers for in-vivo skin diagnostics: some recent developments," Proceedings of SPIE 11047, 1104703 (2019).

105.J. Spigulis, V. Lukinsone, I. Oshina, E. Kviesis-Kipge, M. Tamosiunas, and A. Lihachev, "Riga Group's recent results on laser applications for skin diagnostics,” Journal of Physics: Conference Series 1859, 012033 (2021).

106. The $15^{\text {th }}$ International School on Quantum Electronics "Laser physics and applications", 2008 (accessed 21 Nov 2021) [http://www.icsqe2020.ie-bas.org/sqe2008/index.htm].

107.23 ${ }^{\text {rd }}$ Annual International Laser Physics Workshop - LPHYS'2014. Local Organizing Committee, 2014 (accessed 21 Nov 2021) [https://www.lasphys.com/workshops/lasphys14/local-organizing-committee].

108.26 ${ }^{\text {rd }}$ Annual International Laser Physics Workshop - LPHYS'2017. Advisory and Program Committee, 2017. (accessed 21 Nov 2021) [https://www.lasphys.com/workshops/lasphys17/advisory-program-committee].

109.E. Borisova, H. Schneckenburger, and A. Priezzhev, "Special Section on Laser Technologies for Biomedical Applications," Journal of Biomedical Optics 17 (10), 101501 (2012).

110.R. Robinson, "Ekaterina Borisova on Creativity," Optics \& Photonics News, 28 January 2020 (accessed 21 Nov 2021) [https://www.optica-opn.org/home/career/2020/january/ekaterina_borisova_on_creativity/]. 